\title{
Treatment of Psychotic Symptoms in Parkinson's Disease
}

Felix-Martin Werner ${ }^{1,2,{ }^{*}}$ and Rafael Coveñas ${ }^{2}$

${ }^{1}$ Higher Vocational School of Elderly Care and Occupational Therapy, Euro Academy, Pößneck, Pößneck, Thuringia, 07381, Germany

${ }^{2}$ Laboratory of Neuroanatomy of the Peptidergic Systems (Lab. 14), Institute of Neurosciences of Castilla y León (INCYL), University of Salamanca, Salamanca, CastillaLeón, 37007, Spain

*Corresponding author: Felix-Martin Werner, University of Salamanca, Instituto de Neurociencias de Castilla y León (INCYL), Laboratorio de Neuroanatomía de los Sistemas Peptidérgicos (Lab. 14), c/ Pintor Fernando Gallego, 1, 37007-Salamanca, Spain, Tel: +34/923/29 44 00, extn. 1856; Fax: +34/923/29 45 49; E-mail: felixmwerner@versanet.de

Rec date: Jan 26, 2015, Acc date: Jan 28, 2015, Pub date: Jan 30, 2015

Copyright: ( 2015 Werner FM, et al. This is an open-access article distributed under the terms of the Creative Commons Attribution License, which permits unrestricted use, distribution, and reproduction in any medium, provided the original author and source are credited.

\begin{abstract}
The treatment of Parkinson's disease with I-dopa and a decarboxylase inhibitor, with dopamine agonists or with NMDA antagonists can cause psychotic symptoms. Neural networks are described in the mesolimbic system in order to explain this adverse effect. The psychotic symptoms are treated with second-generation antipsychotic drugs which do not worsen movement disturbances. Among these drugs, the administration of clozapine and quetiapine is recommended to treat psychotic symptoms in Parkinson's disease.
\end{abstract}

Keywords: Parkinson's disease; Psychosis; Second-generation antipsychotic drugs; Dopamine; Serotonin; Clozapine; Quetiapine

\section{Introduction}

Parkinson's disease is a neurodegenerative disease with a dopamine and GABA deficiency and a glutamate and acetylcholine surplus in the extrapyramidal system [1]. A pharmacological treatment is started, if the symptoms rigidity, akinesia and tremor appear [1]. The disease is treated with l-dopa and a decarboxylase inhibitor which increase dopamine levels in the extrapyramidal system, i.e. substantia nigra and putamen, or with dopamine agonists which activate dopamine receptors, especially the $\mathrm{D}_{2}$ receptor [1]. If movement disturbances get worse, NMDA antagonists, for example amantadine can be administered as an additional therapy. Glutaminergic neurons inhibit presynaptically $\mathrm{D}_{2}$ dopaminergic neurons in both the putamen and the substantia nigra and activiate M4 cholinergic neurons in the putamen [2]. Therefore, an NMDA antagonism improves dopamine deficiency via $\mathrm{D}_{2}$ receptors and an acetylcholine surplus via $\mathrm{M}_{4}$ receptors [2]. As a consequence of the described pharmacological treatment, Parkinsonian patients can show psychotic symptoms during the course of the treatment [3]. Several questions arise, why these pharmacological agents can cause these psychiatric symptoms and how to treat adequately psychosis in Parkinson's disease [3]

\section{Neural Networks in the Mesolimbic System}

In order to answer the questions why anti-Parkinsonian drugs can cause psychotic symptoms and how to treat adequately these symptoms, neural networks are described in the mesolimbic system [3]. In this system, GABAergic neurons weakly inhibit dopaminergic neurons via $\mathrm{GABA}_{\mathrm{A}}$ receptors and thus allow a high dopamine activity. Dopaminergic neurons are connected via $D_{2}$ receptors to glutaminergic neurons, which weakly inhibit serotonergic neurons via NMDA receptors. Serotonergic neurons exert a high activity, via 5$\mathrm{HT}_{2 \mathrm{~A}}$ receptors, and are connected to GABAergic neurons. In the A10 cell group, dopaminergic and serotonergic neurons activate each other via $\mathrm{D}_{2}$ or $5-\mathrm{HT}_{2 \mathrm{~A}}$ receptors.
L-dopa and a decarboxylase inhibitor or dopamine agonists can lead to psychotic symptoms in Parkinsonian patients during the course of the treatment, because they increase dopamine levels in the mesolimbic system and cause dopamine hyperactivity. NMDA antagonists can cause psychotic symptoms as well, because a reduced glutaminergic inhibition via NMDA receptors of $5-\mathrm{HT}_{2 \mathrm{~A}}$ serotonergic neurons in the mesolimbic system can cause $5-\mathrm{HT}_{2 \mathrm{~A}}$ serotonin hyperactivity [4]. Psychosis occurs in 20 to $40 \%$ of Parkinsonian patients. These symptoms worsen patients' quality of life. The most frequent psychotic symptoms are visual hallucinations [4]. Another strategy to improve psychotic symptoms is to reduce the dosage of the anti-Parkinsonian drugs [4].

\section{Results}

If Parkinsonian patients develop psychosis, second-generation antipsychotic drugs (SGAs) are administered. The following SGAs are prefered, because they do not worsen movement disturbances [4] (Figure 1):

- Clozapine, which blocks $\mathrm{D}_{3}, \mathrm{D}_{4}$ and $5-\mathrm{HT}_{2 \mathrm{~A}}$ receptors and does not interfere with movement disturbances.

- Quetiapine, which weakly blocks $\mathrm{D}_{2}$ receptors and exerts the main antipsychotic effect by blocking $5-\mathrm{HT}_{2 \mathrm{~A}}$ receptors.

The adverse effects of clozapine are: the development of type two diabetes mellitus, an increase in blood pressure, weight gain and agranulocytosis (this appears in 3\% of patients). The adverse effects of quetiapine are: an increase in the level of blood sugar, an increase in blood pressure and the appearance of a cardiac heart disease $[5,6]$.

\section{Discussion}

Psychotic symptoms, above all visual hallucinations occur in 20 to $40 \%$ of the Parkinsonian patients treated with dopaminergic or antiglutaminergic anti-Parkinsonian drugs [2-5]. These psychiatric symptoms are treated with SGAs. Among these SGAs, clozapine and quetiapine are the drugs of choice, because they do not worsen movement disturbances [2,4-6]. The adverse effects, above all 
Citation: Werner FM, Covenas R (2015) Treatment of Psychotic Symptoms in Parkinson's Disease. J Cytol Histol 6: e115. doi:

Page 2 of 2

metabolic effects, can again deteriorate patients' quality of life [6] Novel options in the treatment of Parkinson's disease can be suggested: for example, to combine 1-dopa and a decarboxylase inhibitor or dopamine agonists with $5-\mathrm{HT}_{2 \mathrm{~A}}$ receptor antagonists, which improve the motor symptoms and do not cause psychotic symptoms, but exert a slight antipsychotic effect [1]. Because $5-\mathrm{HT}_{2 \mathrm{~A}}$ antagonists improve motor symptoms by increasing dopamine levels in the putamen through a reduced presynaptic glutaminergic inhibition via NMDA receptors and because in the mesolimbic system these antagonists exert a slight antipsychotic effect through an $5-\mathrm{HT}_{2 \mathrm{~A}}$ receptor antagonism, they are less likely to produce psychotic side effects in combination with 1-dopa or dopamine agonists. In the mesolimbic system, NMDA antagonists are likely to produce psychotic symptoms, because they induce serotonin hyperactivity through a reduced presynaptic inhibition.

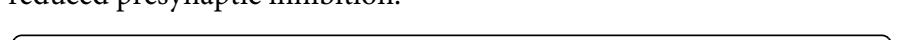

The mesolimbic system in Parkinson's disease

\section{Mesolimbic system}

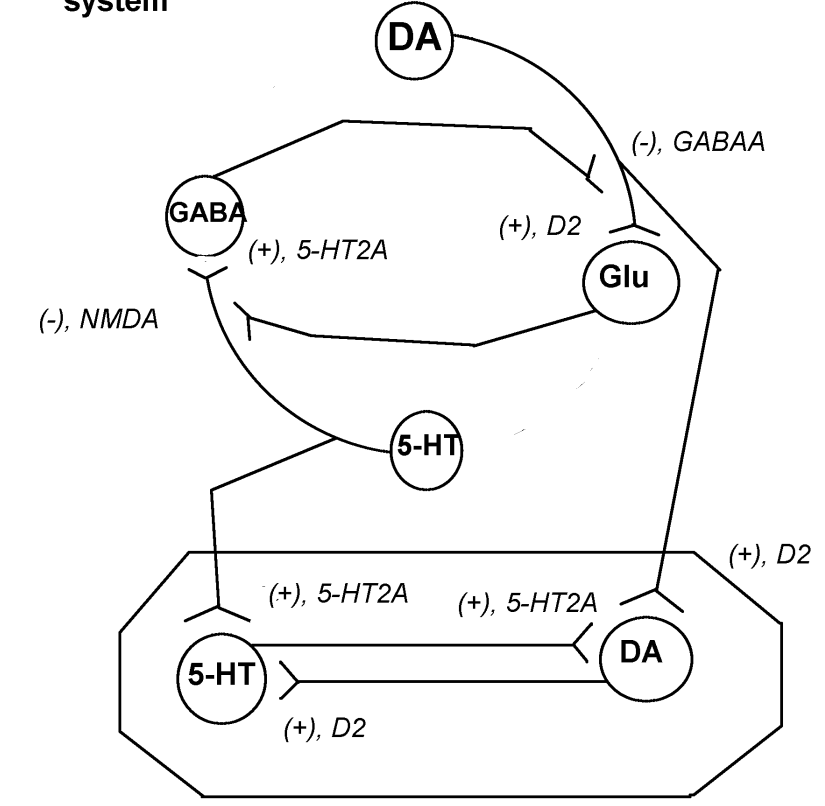

A10 cell group

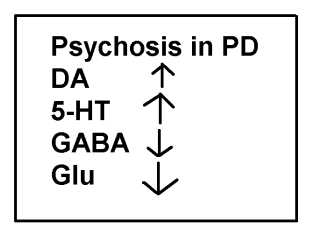

Figure 1: Effect of antagonists on the mesolimbic system in Parkinson's disease.

This article was originally published in a special issue, entitled: "\$ \{spllssueContent\}", Edited by $\$\{$ spllssueAuthor\}

\section{References}

1. Werner FM, Coveñas R (2014) Classical Neurotransmitters and Neuropeptides Involved in Parkinson's disease: A MultiNeurotransmitter System. J Cytol Histol 5: 5.

2. Werner FM, Coveñas R (2012) Possible therapeutic options in Parkinson's disease according to a neuronal network. Neurologie \& Rehabilitation 18: 420-421.

3. Werner FM, Coveñas R (2012) Treatment of psychosis in Parkinson's disease according to a neuronal network. MDPD congress, abstract-CD.

4. Bizzarri JV, Giupponi G, Maniscalco I, Schroffenegger P, Conca A, et al. (2015) Parkinson's disease and psychoses. Neuropsychiatr. [Epub ahead of print].

5. Thomas SP, Nandhra HS, Singh SP (2012) Pharmacologic treatment of first-episode schizophrenia: a review of the literature. Prim Care Companion CNS Disord 14.

6. McKean A, Monasterio E (2015) Indications of atypical antipsychotics in the elderly. Expert Rev Clin Pharmacol 8: 5-7. 